\title{
ПРОБЛЕМЫ ИНВЕСТИРОВАНИЯ В ИННОВАЦИОННОМ РАЗВИТИИ ЭКОНОМИКИ УЗБЕКИСТАНА
}

\author{
Хамракулова О.Д. \\ к.э.н., дои. кафедры «Банковское дело», \\ Самаркандского института экономики и сервиса \\ Рашидов Б. \\ студ.гр. БX-217 \\ Самаркандского института экономики и сервиса.
}

\begin{abstract}
Аннотация. В работе рассмотрены проблемы инвестиций в инновационном развитии экономики Узбекистана, а также предложены рекомендации.

Abstract. The paper deals with the problems of investment in the innovative development of the economy of Uzbekistan, and offers recommendations.

Ключевые слова : инвестиции, инновационный путь развития.

Key words: innovation, investment.
\end{abstract}

Важное место в развитии экономики Узбекистана занимает вопрос инновационного развития рыночной экономики. Были приняты ряд документов, таких как Стратегия инновационного развития Республики Узбекистан на 2019-2021 годы, Государственная программа по реализации Стратегии действий по пяти приоритетным направлениям развития Республики Узбекистан в 2017-2021 годы в «Год развития науки, просвещения и цифровой экономики»(2020 год) в которых определены необходимость, условия и перспективы развития нашей страны. [1]

В настоящее время инновационное развитие становится наиболее важным элементом социальноэкономического развития странам и регионов мирового хозяйства. Рост экономик США, ЕС, Японии, Южной Кореи, Китая, Индии во многом обусловлен развитием наукоемких отраслей, разработкой и внедрением инноваций. Без инноваций экономическая система не достигла бы устойчивого равновесия, которое будет препятствовать дальнейшему развитию национальной экономики.

В Узбекистане, как и в других государствах мирового сообщества, проводится работа по модернизации, техническому и технологическому перевооружению промышленного производства, вовлечению в этот процесс академической и отраслевой науки.

В этой связи, важную роль в становлении инновационного развития экономики Узбекистана принадлежит инвестициям, их активной роли в ускорении социально-экономического развития страны, повышению жизненного уровня населения.

В рамках реализуемых и перспективных новых инвестиционных проектов в 2019-2025 г. предполагается освоение нецентрализованных инвестиций в объеме свыше 80 млрд. долл., из которых около $30 \%$ будет профинансировано за счет собственных средств предприятий.

В результате проведения вышеуказанных мер, в период 2019-2025 гг. ожидается увеличение доли инвестиций в основной капитал в ВВП с 26\% до 28-30\%, соответственно. При этом ожидается, что в 2025 г. объем привлеченных прямых иностранных инвестиций составит 6,7 млрд.долл. по сравнению с 1,8 млрд. долл в 2018 г [2].

В экономической литературе проблемы инвестирования привлекают особое внимание ученых. Так, английский экономист Дж.М.Кейнс в своей знаменитой работе «Общая теория занятости, процента и денег»( 1936 год) впервые анализировал потребление, сбережение и инвестиции, раскрыл сущность мультипликатора.

Анализ использованной литературы. Современные экономисты продолжают исследовать инвестиционные процессы. Так, американские экономисты Стэнли Л. Брю и Кэмпбелл Р. Макконнелл выделяют «инвестиционные расходы как вторую основную детерминанту совокупного спроса»; причем выделяют 2 параметра « процентные ставки и ожидаемые прибыли [3].

Теоретики российской экономической науки, такие как Седов В.В. рассматривают инвестиции как интегральный фактор экономического роста [4]; коллектив авторов под руководством Камаева В.Д. делают упор на инвестиционный акселератор [5] .Прочие исследователи по инвестированию, в частности, изучающие иностранные инвестиции (Андрианов А.Ф., Иванов В.А.), рассматривают их чисто в прикладном характере (например, для экономики России), нет рекомендаций общетеоретического характера $[5,6$.

Активный инвестиционный процесс предопределяет экономический потенциал страны в целом, способствует повышению жизненного уровня населения.

Методология исследования. В работе использован абстрактный метод, а также математические и статистические методы. 
Анализ и результаты. Роль и значение инвестиций в развитии экономики огромны. На общеэкономическом уровне инвестиции требуются для: расширения воспроизводства, структурных преобразований в стране, повышения конкурентоспособности отечественной продукции, решения социально-экономических проблем, в частности, проблем безработицы, образования, здравоохранения, экологии и т.д.

На микроуровне инвестиции способствуют: развитию и укреплению позиций компании, обновлению основных фондов, стабилизации финансового состояния, повышению конкурентоспособности предприятия, повышению квалификации кадров, совершенствованию методов управления.

В рыночной экономике государство активно участвует в регулировании инвестиционной деятельности, которое находит свое проявление в следующем:

во-первых, государство выступает в качестве системообразующего фактора, так как создает нормативно правовую базу. Инвестиционное законодательство в Узбекистане является одним из передовых в системе законодательства стран СНГ, который включил в себя основные положения международного инвестиционного права

во-вторых, само государство является субъектом инвестиционной деятельности, выделяя бюджетные средства на конкурсной основе непосредственным инвесторам. При этом государство при принятии инвестиционных решений руководствуется иными принципами, чем коммерческие организации при оценки эффективности реальных проектов.

в - третьих, государство определяет стратегию поведения инвесторов на рынке инвестиционных товаров, объем и структуру государственных инвестиций.

Конечные (стратегические) цели определяют степень воздействия данной формы финансовой и денежно кредитной политики на производство. «...Инвестиционное решение по своей сути является результатом сопоставления предельных выгод и предельных затрат» [3.]

В Узбекистане принята комплексная Концепция социально-экономического развития страны до 2030 года, которая предусматривает обеспечение макроэкономической стабильности и устойчивости экономического роста, повышение конкурентоспособности, инвестиционного и экспортного потенциала отраслей экономики, создание благоприятных условий для развития и защиты предпринимательства, снижение уровня напряженности на рынке труда, рост доходов населения и сокращение мало обеспеченности.[ 7]

Поэтому разработанная Концепция, учитывающая тенденции развития мировой экономики, меры по сглаживанию воздействия на экономику страны негативных внешних факторов, демографических тенденций и напряженности на рынке труда, необходимость наращивания производственного потенциала территорий, обеспечение роста занятости и улучшение условий жизни населения рассматривается важным ориентиром в комплексном решении вопросов перехода экономики страны на путь устойчивого развития и повышения благосостояния населения.

Но необходимо отметить, кроме удобного географического расположения в центре региона, богатого природного и минерально-ресурсного потенциала, Узбекистан обладает развитой промышленнопроизводственной базой.

За период 2009-2018 гг. в республике только в рамках инвестиционных программ реализовано 221 крупных инвестиционных проектов на общую сумму 21,4 млрд. долл..[2]

Однако в инвестиционной политике Республики Узбекистан также существуют определенные недостатки, которые способствуют медленному развитию экономики и самой страны в целом. Существуют такие недостатки как: недостаток инвестиций в основной капитал, недостаточная инвестиционная привлекательность, динамика иностранных инвестиций недостаточна для ускорения экономического роста, нет четкого механизма по координации инвестиционного рынка, не работают новые механизмы, нацеленные на инновационное развитие экономики.

Кроме этого необходимо отметить, что COVID -19 внес существенные проблемы в экономику страны, так как не секрет, что мировая экономика впала в глубокий экономический кризис, инновации же позволят решить проблемы экономического роста, занятости, роста доходов населения.

Исходя из реальных условий, в Узбекистане в 2020 году с учетом международных стандартов были определены конкретные изменения в направлениях по освоению инвестиций:

- 34\% иностранных инвестиций будут направлены на дальнейшее развитие основных секторов экономики, определяющих фундамент экономики;

- будет проведена оптимизация расходов на инвестиционные проектов, перераспределены ресурсы в объеме 450 млрд. сум. из Инвестиционной программы на другие цели: освоение 40 тыс.га земель, создание 80 тыс. рабочих мест;

- создание условий для поддержки отечественных инвесторов, распространение преференций для иностранных и местных инвесторов;

-использование электронных платформ для обеспечения некоторых ключевых услуг, использовать инструменты электронной регистрации ЮНКТАД. 
Более детальная конкретизация направлений инвестирования была вызвана реальными условиями и тенденциями развития мировой экономики в условиях пандемии коронавируса.

Кроме этого, необходимо отметить, что в инвестиционной политике нашего государства еще существуют определенные недостатки, которые способствуют недостаточному развитию экономики. Это такие недостатки как: недостаток инвестиций в основной капитал, недостаточная инвестиционная привлекательность, динамика иностранных инвестиций недостаточна для ускорения экономического роста, нет четкого механизма по координации инвестиционного рынка, не работают новые механизмы, нацеленные на инновационное развитие экономики. Помимо этого нельзя не учесть влияние мирового кризиса, связанного с пандемией корона вируса, которая требует принятия мер по защите важных отраслей экономики, а также проведения гибкой инвестиционной политики.

В Узбекистане принята Инвестиционная программа на 2021-2023 годы, которая включает:

- сводные прогнозные параметры освоения капитальных вложений в 2021-2023 гг., а также прогнозные параметры освоения и привлечения инвестиций и кредитов в 2021-2023 гг., предусматривающие освоение централизованных и нецентрализованных инвестиций в размере 928,7 трлн сумов, в том числе $\$ 37,5$ млрд иностранных инвестиций;

- адресную программу ввода крупных производственных объектов и мощностей в 2021 году, предусматривающую создание 226 новых производственных мощностей и более 34 тыс. рабочих мест.

- перечень инвестиционных проектов, по которым требуется разработка, согласование и утверждение предпроектной и проектной документации в 2021 году;

- перечень перспективных инвестиционных проектов, подлежащих проработке в 2021 году.

В 2021 году Узбекистан планирует освоить \$23 млрд инвестиций. "Таким образом мы четко понимаем, на что пойдет каждый из этих 23 миллиардов долларов инвестиций. В частности, в 2021 году планируется запуск 226 промышленных и инфраструктурных проектов", — отметил глава государства..[8]

Заключение и предложения: Политика Республики Узбекистан в области развития инновационной системы базируется на равноправном государственно-частном партнерстве и направлена на объединение усилий и ресурсов государства и предпринимателей страны для активизации инновационной деятельности. «Главная цель инновационного развития нашей страны - это развитие человеческого капитала; до 2030 года Узбекистан в Глобальном инновационном индексе в рейтинге передовых стран должен занять 50 -е место».[1]

Главным ориентиром для нас должно быть непрерывное технологическое и техническое обновление производства, а также постоянный поиск внешних и внутренних резервов, осуществление глубоких структурных преобразований в экономике, модернизации и диверсификации промышленности. Исходя из стратегических направлений перехода на инновационный путь развития, мы считаем необходимым:

- создание четкого механизма инновационного развития на среднесрочную и долгосрочную перспективу, причем использовать систему стратегического планирования, позволяющей формировать будущие модели инновационного развития приоритетных сфер и отраслей на основе долгосрочных сценариев повышения интеллектуального и технологического потенциала страны.

В этой связи, необходимо:

- применять опыт других стран, так в мае 2020 года в Женеве прошло обсуждение инвестиционной политики Узбекистана в виде видеоконференции, на которой были представлены ряд стран ООН. Такая организация как ЮНКТАД (конференция ООН по торговле и развитию) готовы оказать содействие Узбекистану в создании электронного портала;

- использовать экономический механизм внедрения инновационных форм государственного управления, обеспечивающих оптимизацию и упрощение процедур оказания государственных услуг, повышение эффективности деятельности органов государственного управления (использование четкого механизма по расширению государственно-частного партнерства, развития цифровой экономики);

- расширить условия для привлечения инвестиций в сферу разработки и внедрения инновационных идей и технологий, совершенствование нормативно-правовой базы, обеспечивающей их дальнейшее развитие, использовать возможности международных финансовых организаций по привлечению инвестиций в инновации;

- поддерживать и стимулировать научно-исследовательскую и инновационную деятельности, прежде всего творческих идей и разработок молодого поколения, а также создание благоприятных условий для активного участия талантливой молодежи в данной деятельности; разработать комплексную программу по привлечению молодежи в инновационный процесс страны;

- создать эффективные механизмы продвижения и внедрения перспективных отечественных достижений научно-исследовательской и инновационной деятельности, включая организацию и укрепление материальнотехнической базы научно-экспериментальных специализированных лабораторий, центров высоких технологий, технопарков и других инновационно - ориентированных структур, в том числе с участием иностранных инвесторов.

\section{ЛИТЕРАТУРА:}


1. Указ Президента РУ «О стратегии инновационного развития Республики Узбекистан на 2019-2021 годы.», Государственная программа по реализации Стратегии действий по пяти приоритетным направлениям развития Республики Узбекистан в 2017-2021 годы в «Год развития науки, просвещения и цифровой экономики» Народное слово, 22.09.2018

2. Стратегия инвестиционной политики Узбекистана до 2025 года.- , www. Uza. Uz

3. Брю С.Л., Макконнелл К.Р. Экономикс: краткий курс: пер. 1-го анг.изд-М., ИНФРА, 2015,462c

4. Седов В.В. Экономическая теория. Учебное пособие. Челябинск, 2014, 115с.

5. Камаев В.Д., Ильчиков М.З., Борисовская Т.А. Экономическая теория. Краткий курс.М, Кнорус, 2016, 384с.

6. Андрианов А.Ф. и другие. Инвестиции.: Электронный учебник.- М : Кнорус, 2016, 565с. o

нслание Президента РУ Ш. Мирзиёева к Олий Мажлису от $29.12 \quad 2021$ года -

MV

(1)

M

SI

p

$\mathbf{H}$ 